\title{
Psicoterapia, neuroplasticidade e o funcionamento cerebral
}

\section{Psychotherapy, neuroplasticity and brain functioning}

DOI: $10.46919 / \operatorname{archv2n1-009}$

Recebimento dos originais: 30/10/2020

Aceitação para publicação: 23/12/2020

\author{
Mario Sergio Bruggmann \\ Enfermeiro. Especialista em Psicoterapia. Doutorando em Enfermagem. \\ Instituição: Programa de Pós-Graduação em Enfermagem da Universidade Federal de Santa Catarina \\ (UFSC). \\ Endereço: Rua Delfino Conti, Trindade, Florianópolis, Santa Catarina - Brasil. \\ E-mail: mariobrugg@gmail.com
}

\begin{abstract}
RESUMO
Trata-se de uma revisão narrativa da literatura, cujo objetivo é descrever a relação entre psicoterapia, neuroplasticidade e o funcionamento cerebral. Ao realizar as buscas em diferentes bases de dados, evidenciou-se que as psicoterapias são emergentes de um longo processo histórico, associado à construção do conhecimento científico. Constituem um recurso terapêutico empregado na área da saúde, se apresentando sob diferentes concepções teóricas e modelos de atuação, estando indicadas ao tratamento de transtornos mentais e problemas de origem emocional, como método de escolha ou adjuvante a outras formas de tratamento. $\mathrm{O}$ curso científico traçado por pesquisadores para compreender o funcionamento cerebral associado à psicoterapia, remonta uma trajetória de significativos progressos, dentre eles o conhecimento sobre a neuroplasticidade, que faz menção à relação entre a experiência, fatores sociais, aprendizado e cérebro. Considera-se, portanto, se que a psicoterapia tem papel preponderante na modificação do funcionamento cerebral por meio da plasticidade neuronal, conforme evidenciado por estudos de neuroimagem. Para tanto, sugere-se que sejam realizadas mais investigações sobre o impacto da psicoterapia no funcionamento cerebral, especialmente, para refinar o arsenal científico que abrange os transtornos mentais e a prática na clínica do psicoterapeuta.
\end{abstract}

Palavras-chave: Psicoterapia, Neuroplasticidade, Neurociências, Cérebro.

\begin{abstract}
It is a narrative review of the literature, whose objective is to describe the relationship between psychotherapy, neuroplasticity and the brain functioning. When performing searches in different databases, it became evident that psychotherapies are emerging from a long historical process, associated with the construction of scientific knowledge. They constitute a therapeutic resource used in the health area, presenting themselves under different theoretical conceptions and models of action, being indicated for the treatment of mental disorders and problems of emotional origin, as a method of choice or adjunct to other forms of treatment. The scientific course designed by researchers to understand the brain functioning associated with psychotherapy, goes back to a trajectory of significant progress, among them knowledge about neuroplasticity, which mentions the relationship between experience, social factors, learning and the brain. Therefore, it is considered that psychotherapy has a preponderant role in modifying brain functioning through neuronal plasticity, as evidenced by neuroimaging studies. Therefore, it is suggested that further investigations are carried out on the impact of psychotherapy on brain functioning, especially to refine the scientific arsenal that encompasses mental disorders and the practice in the psychotherapist's clinic.
\end{abstract}

Keywords: Psychotherapy, Neuroplasticity, Neurosciences, Brain. 


\section{INTRODUÇÃO}

As psicoterapias configuram um importante recurso terapêutico utilizado no campo da saúde e possuem a mesma relevância científica de tratamentos medicamentosos ou intervencionistas. Elas se apresentam sob diferentes concepções teóricas e modelos de atuação, estando indicadas para o tratamento de transtornos mentais e problemas de origem emocional, seja como método de escolha ou como adjuvante a outras formas terapêuticas.

Historicamente, as psicoterapias foram questionadas sobre a sua resolutividade frente aos problemas de saúde mental, porém, atualmente, são amplamente aceitas como tratamento efetivo a diferentes problemas de origem psiquiátrica e psicológica. Após décadas de investigação em um cenário ainda pouco conhecido, resultados de pesquisas sobre psicoterapias começaram a ganhar força e diversos estudos de grande impacto científico evidenciaram sua eficácia como tratamento de problemas psiquiátricos e psicológicos. ${ }^{1}$

Transcendendo a eficácia comprovada das psicoterapias e seus impactos nos problemas de saúde mental, neurocientistas buscam através de diferentes pesquisas, clarificar cada vez mais, como a psicoterapia atua no cérebro humano, quais são as modificações e como elas ocorrem. ${ }^{1}$

Para isso, estudiosos das neurociências investigam um fenômeno conhecido como neuroplasticidade ou plasticidade neuronal, que é um conceito empregado para explicar a relação entre fatores sociais, aprendizado e cérebro. ${ }^{2}$ Ou seja, o termo refere-se à capacidade do cérebro para se reorganizar e se adaptar ao longo da vida, mediante as diferentes experiências pelo qual a pessoa é submetida. ${ }^{3}$

A neuroplasticidade também é compreendida como a capacidade que o sistema nervoso tem de se modificar e se adaptar, a partir de experiências pessoais de diferentes contextos. ${ }^{2}$ Diante desta concepção, a psicoterapia, ao promover um cenário favorável à aprendizagem e mudança do comportamento humano, está alterando, também, as funções neurofisiológicas.

De acordo com a literatura, a plasticidade neuronal se mantém estreitamente relacionada ao conceito de epigenética, que se refere sinteticamente à regulação da estrutura e função do material genético de um ser vivo sem alterar a sequência de seu DNA. Neste sentido, vale destacar que através da epigenética, compreende-se que inúmeros fatores internos e externos delineiam o sistema genético de um ser vivo durante sua vida. ${ }^{1,4}$

Com base no desenrolar das descrições supramencionadas, aponta-se a seguinte questão norteadora: existe relação entre psicoterapia, neuroplasticidade e o funcionamento cerebral? Para este questionamento realizou-se o presente estudo, que trata-se de uma revisão narrativa de literatura, cujo objetivo é descrever a relação entre psicoterapia, neuroplasticidade e o funcionamento cerebral.

Nesta perspectiva, justifica-se a realização desta pesquisa bibliográfica, pois considera-se que ela poderá contribuir com uma lacuna de conhecimento existente neste campo de atuação. Além disso, vale 
mencionar que o presente estudo possui relevância para o cenário científico e social, por discorrer sobre questões inerentes às psicoterapias, neuroplasticidade, funcionamento cerebral e modificação do comportamento humano.

\section{ASPECTOS HISTÓRICOS E ORIGEM DA PSICOTERAPIA}

Os diferentes modelos de intervenção aplicados na área de saúde mental vêm passando por importantes transformações ao longo da história, por meio de estudos que conferem maior evidência científica e, consequentemente, auxiliam na construção de políticas públicas de saúde mais consistentes. ${ }^{5}$ Esta evolução é natural e acontece porque as necessidades da sociedade não são estáticas, conferindo-lhe de tempos em tempos, novas verdades vigentes que ressignificam suas percepções de mundo.

Neste sentido, pode-se dizer que estudiosos nos campos da saúde mental e psiquiatria vem acompanhando esta reestruturação social e também passaram a direcionar um novo olhar sobre as necessidades das pessoas com transtornos mentais, incluindo observações mais abrangente sobre as diferentes formas de sofrimento humano e tratamentos mais seguros.

O termo psicoterapia tem origem nas palavras gregas Psykê (mente) e Therapeuein (curar), e desde o final do século XIX, vem sendo empregada como recurso terapêutico e tratamento para os diferentes transtornos mentais ('cura pela fala'). ${ }^{6}$

Com base na sua historicidade, muitas tentativas de intervenções psicoterápicas remetem aos séculos XVIII e XIX, e grande parte delas se aproximava do charlatanismo. Todavia, destaca-se a reconhecida intervenção do magnetismo animal, proposta pelo médico austríaco Franz Anton Mesmer. Este profissional defendia que o transtorno mental era decorrente de um desequilíbrio do campo magnético corporal que desajustava os elementos contidos no sangue, que poderia ser revertido com o uso de pedras de propriedades magnéticas. Além deste método, o médico supramencionado utilizava longas sessões catárticas grupais que envolviam técnicas hipnóticas. ${ }^{1}$

O emprego da sugestão e da hipnose de modo heurístico foi o impulso para ressaltar o termo "psicoterapêutico", usado pelo médico inglês Daniel Hack Tuke no livro intitulado Illustrations of the In_uence of the Mind upon the Body in Health and Disease: Designed to Elucidate the Action of the Imagination, de 1872. ${ }^{1}$

A psicanálise, modelo proposto por Sigmund Freud no final do século XIX, se apresenta como o primeiro modelo de psicoterapia estruturada e, apesar das críticas e resistência dos meios acadêmicos na Europa e Estados Unidos, ela continuou sendo o modelo hegemônico de psicoterapia até a primeira metade do século XX. ${ }^{1}$

Com base nesta construção epistemológica, também é significativo fazer uma síntese dos principais modelos psicoterápicos, conforme sua concepção teórica e recorte histórico: 
Modelo psicanalítico, criado por Freud, que leva em conta o determinismo dos conflitos psíquicos inconscientes e dos mecanismos de defesa do ego sobre os sintomas mentais e a conduta humana; o modelo comportamental, que foca as formas de comportamento aprendido e condicionado de Pavlov, Watson, Skinner, Wolpe e Bandura; modelo cognitivo, desenvolvido por Ellis e Aaron Beck, que enfatiza o papel de cognições disfuncionais como fator responsável pelos sintomas depressivos e ansiosos; modelo existencial/humanista/centrado na pessoa, de Carl Rogerse Viktor Frankl, que, fundamentado na fenomenologia e no existencialismo, propõe que o sofrimento humano decorre da perda de significado existencial; modelo dos fatores comuns ou não específicos, proposto por Jerome Frank, que preconiza que a boa relação, a empatia e o calor humano com o paciente são suficientes para melhorar os sintomas; modelo dos fatores biopsicossociais, proposto originalmente por George Engel (1913-1999), que preconiza que fatores biológicos, psicológicos e sociais determinam todas as doenças mentais e que fundamentou intervenções específicas para os diferentes fatores, como a terapia interpessoal, a terapia familiar e a terapia de grupo. ${ }^{1: 55}$

De acordo com as considerações descritas sobre o contexto histórico e evolução da psicoterapia no cenário mundial, sinaliza-se que, diferentemente do final do século XIX, quando a psicanálise era o único formato de psicoterapia, atualmente dispõe-se de distintas modalidades psicoterápicas e um maior arsenal científico sobre elas. ${ }^{7}$ Outrossim, a eficácia das abordagens psicoterápicas vem sendo comprovada com o auxílio da neurociência, estudos clínicos randomizados, meta-análises e exames de neuroimagem. Deste modo, a psicoterapia se configura como um relevante método de tratamento para os transtornos mentais de um modo geral, para a busca do autoconhecimento e melhor qualidade de vida. ${ }^{1}$

\section{A RELAÇÃO ENTRE MENTE, CÉREBRO, APRENDIZADO E PSICOTERAPIA}

A psicoterapia é uma intervenção que objetiva identificar, reflexionar e tratar os problemas de natureza emocional, cognitiva e comportamental, modificando-os. Neste entendimento, a psicoterapia assume um papel relevante nos estudos que apontam o homem como um ser passível de transformação biológica e psicológica, a partir da exposição a experiências. Assim, diferentes princípios biológicos foram propostos para explicar como a psicoterapia modifica o funcionamento cerebral, dentre eles, as técnicas de neuroimagem. ${ }^{1}$

Para uma compreensão mais ampla deste processo, considera-se apontar a complexa relação que existe entre mente e cérebro, que são descritas pelo menos por duas posições filosóficas distintas. O dualismo, que faz menção à mente e o cérebro como estruturas totalmente separadas e o monismo que considera as duas estruturas como única, sendo a mente um produto da atividade do cérebro. Todavia, "além dessa divisão conceitual, pode-se ainda classificar as perspectivas que abordam tal questão como: dogmática, eclética, pluralista e integralista". 1:97

A perspectiva dogmática refere que existe apenas uma explicação razoável para a relação mente e cérebro: "ou uma teoria psicológica esclarece totalmente a relação mente-cérebro, ou uma teoria biológica a justifica". O materialismo eliminativo é uma amostra da teoria biológica, apontando que a realidade mental é considerada pela existência das conexões neuronais no encéfalo. 1:97 
Os ecléticos assinalam que a abordagem integralmente psicológica ou biológica não pode ser estabelecida, considerando que ambas são necessárias para se discutir sobre mente e cérebro. Uma amostra desta concepção é a proposição biopsicossocial, que coloca os transtornos mentais em perspectivas biológicas e psicossociais não excludentes. Os pluralistas, por sua vez, assinalam que não existe uma abordagem única que permita a compreensão integral da relação mente-cérebro, mas discordam em envolver diferentes abordagens em uma mesma análise. Para os pluralistas, "cada perspectiva deve ser estudada de forma separada da outra". 1: 98

Sob uma perspectiva integralista, Kandel (1998) sintetizou "a relação entre a mente, o cérebro, o aprendizado e a psicoterapia" em cinco princípios: ${ }^{1: 98-101}$

1. Todos os processos mentais derivam de operações do cérebro: para o autor, a mente pode ser entendida como um composto de funções exercidas pelo cérebro e apesar desta concepção ser difundida pela neurociência, as particularidades de como o cérebro determina os diversos fenômenos mentais não são conhecidos. ${ }^{1}$

2. O material genético exerce grande influência sobre o comportamento: os comportamentos são gerados no cérebro, que por sua vez, é construído mediante um programa genético. ${ }^{1}$

\section{Fatores sociais podem modificar o comportamento por meio de alterações na expressão} gênica: determinadas condições sociais, de desenvolvimento, aprendizado e estresse podem atuar no cérebro, modificando a expressão gênica e, por conseguinte, os padrões de conexões neuronais.

${ }^{2}$ Para esta concepção, existem evidências científicas de que abusos e maus-tratos na infância deixam uma forma de registro genético na "regulação epigenética de vários genes", assim como naqueles que regulam a formação de receptores de glicocorticoides. Este fato está diretamente relacionado ao possível aumento de risco para depressão e suicídio. 1: 99, 4

\section{Alterações na expressão genética induzidas pelo aprendizado promovem mudanças nas} conexões neurais: a experiência e o aprendizado proporcionam alterações na expressão gênica e isso pode ser compreendido através da plasticidade sináptica, ou seja, o fortalecimento ou enfraquecimento de uma sinapse dependendo de sua atividade. ${ }^{8}$ Assim, certifica-se que tanto a sequência do material genético como as experiências que o homem vivencia, impactam no desenvolvimento do seu comportamento. ${ }^{1}$

\section{A psicoterapia altera a expressão gênica e, assim, a forma e a função cerebrais: a psicoterapia} traz modificações nos padrões do comportamento humano por meio de alterações na expressão de genes que levam a modificações no cérebro. ${ }^{9}$ Para corroborar esta afirmação, um estudo realizado por Maguire et al. (2000) ${ }^{10}$, que identificou variação na expressão genética em células sanguíneas antes e após psicoterapia de exposição prolongada em pessoas com transtorno de estresse póstraumático, evidenciou que: 
Após a terapia, houve alteração na expressão do gene FKBP5, que orienta a produção de uma proteína envolvida na transmissão de mensagens intracelular do gene de receptores de glicocorticoide. Essa alteração se correlacionou com melhora clínica. Tal achado oferece evidência preliminar do efeito da psicoterapia na regulação da expressão genética em transtornos mentais. ${ }^{1:}$

Apoiado nas considerações ora descritas, é valido apontar que a psicoterapia possui papel preponderante e influencia ativamente a atividade cerebral de pessoas com transtornos mentais, estimulando ativações neurofisiológicas que impactam diretamente em mudanças comportamentais. Para corroborar este fato, salienta-se que a evolução da neurociência foi um marco importante para esta comprovação e segue fornecendo subsídios que fomentam discussões sobre a influência da psicoterapia na modificação do funcionamento cerebral. ${ }^{1}$

\title{
4 NEUROPLASTICIDADE
}

Para fins de conhecimento, considera-se significativo ressaltar que os termos "neuroplasticidade", "plasticidade cerebral", "plasticidade neuronal" e "plasticidade sináptica" se apresentam como sinônimos, sem prejuízo de entendimento. Todos os conceitos descritos concebem a noção de capacidade adaptativa do cérebro frente a diferentes condições biopsicossociais. ${ }^{11}$

A neuroplasticidade é um conceito utilizado para explicar a relação entre fatores sociais, aprendizado e cérebro. Ela é compreendida como a habilidade que o cérebro tem de se transformar e se adaptar mediante sucessivas interações e desafios impostos pelo ambiente e pela experiência. ${ }^{2}$ De acordo com os neurocientistas, tem sido verificada a capacidade de transformação do tecido nervoso, além da sua adaptação às exigências externas ou internas do organismo, não somente na fase embrionária e no início da vida, mas também ao longo de todo o ciclo vital. A experiência representa o eixo central que estimula ou limita a plasticidade neuronal. ${ }^{12}$

A plasticidade neuronal pode ser verificada:

\begin{abstract}
Neurogênese, pelo aumento ou redução no tamanho dos dendritos e espinhas dendríticas, pela formação ou eliminação de sinapses, pelo aumento da atividade glial e pelas alterações na atividade metabólica de distintas áreas cerebrais. Pequenas proteínas atuantes no cérebro, as neurotrofinas (NTs), também são importantes para a plasticidade neuronal perante a experiência. São algumas delas: fator de crescimento neuronal (NGF), fator neurotrófico derivado do cérebro (BDNF), NT-3 e NT-4/5. ${ }^{13: 59}$
\end{abstract}

Particularmente associado à experiência, o aprendizado e a memória estão relacionados às modificações sinápticas e ao fortalecimento destas vias. Outrossim, estão associados à concepção de novas sinapses e ao recrutamento de neurônios próximos para formar novas conexões, relacionam-se, assim, à neuroplasticidade derivada da experiência. ${ }^{13}$ 
Neste entendimento, vale ressaltar que esta habilidade cerebral engloba um expressivo campo de saber relacionado ao comportamento e aprendizado, enfraquecimento ou fortalecimento de sinapses e até a neurogênese. ${ }^{14}$ Assim, a plasticidade neuronal segue fortemente relacionada à concepção de epigenética, que é a regulação da estrutura e da função do material genético de um ser vivo, sem modificar a sequência de seu DNA. ${ }^{15}$

Referente à relação da neuroplasticidade às experiências negativas ao longo da vida e aos transtornos mentais, considera-se que as depressões e os transtornos de ansiedade graves e prolongados possuem impacto negativo sobre a plasticidade neuronal. Para tanto, destaca-se que a "liberação de adrenalina e de glicocorticoides endógenos" (cortisol) após o estresse ocasionaria um dano neuronal, especialmente no córtex pré-frontal e no hipocampo, que são regiões ricas em receptores para glicocorticoides e intimamente relacionadas ao aprendizado e à memória. Episódios repetidos, graves e duradouros de depressão foram associados com a diminuição do volume do hipocampo e do córtex. ${ }^{13:} 60$

\section{A MODIFICAÇÃO DO COMPORTAMENTO APÓS A PSICOTERAPIA}

Sobre as modificações do comportamento humano frente as intervenções psicoterápicas, destacamse os seguintes pontos específicos:

\subsection{FATORES COGNITIVOS: PSICOEDUCAÇÃO, REESTRUTURAÇÃO COGNITIVA E INSIGHT}

Atualmente, existe um consenso na literatura sobre o desenvolvimento e aumento das habilidades cognitivas das pessoas submetidas às psicoterapias. Isso ocorre pela incorporação de novas percepções, pelo ajuste das interpretações erradas acerca de si e da realidade adjacente, pelo aumento do autoconhecimento e da habilidade de introspecção, fazendo com que se tenha condições de identificar os diferentes fenômenos mentais (pensamentos, emoções, impulsos, lembranças) e de estabelecer ligações entre eles (insight). Estas habilidades possibilitam que a pessoa lide de forma mais adequada com seus pensamentos, comportamentos e relações, adquirindo maior controle sobre os seus impulsos, planejando a sua vida e tomando decisões mais saudáveis. Além disso, estas habilidades poderão mobilizar recursos bloqueados que contribuirão com a melhora de seus sintomas. ${ }^{16}$

A psicoeducação tem dois objetivos fundamentais: o primeiro é aumentar, de forma segura, o conhecimento da pessoa sobre o seu transtorno mental, seus sintomas, mecanismos envolvidos na origem e perpetuação do problema, tratamentos, prevenção de recaídas e ativação de recursos para lidar com os efeitos adversos; o segundo objetivo é aproximar a pessoa da psicoterapia e estratégias disponíveis para afastar os sintomas. ${ }^{1}$

A reestruturação cognitiva é um processo que se fundamenta na "correção de distorções cognitivas, de percepções e interpretações erradas ou distorcidas como forma de modificar o 
comportamento e as emoções”. Nesta perspectiva, almeja-se que ao longo das intervenções psicoterápicas, aconteçam duas modificações importantes: a "dos pensamentos automáticos e das crenças subjacentes (crenças intermediárias ou crenças nucleares), bem como de esquemas cognitivos disfuncionais". 1: 123

O insigth representa uma habilidade cognitiva fundamental, associado especialmente às psicoterapias de orientação analítica e à psicanálise. É uma palavra que expressa o grau de entendimento que a pessoa tem acerca do seu problema. Pode-se dizer que é uma ampliação do autoconhecimento, onde a pessoa percebe as conexões entre as emoções e comportamentos presentes e relevantes na sua vida. Outro ponto expressivo a se destacar é que a capacidade de ter insight é um importante preditor de resposta à psicoterapia. 1,13

\subsection{FATORES COMPORTAMENTAIS: APRENDIZAGENS}

A construção do conhecimento ao longo da vida do ser humano tem papel expressivo nas modificações cerebrais e, consequentemente, no comportamento humano. É neste sentido que a escola comportamental emprega grande importância às seguintes formas definidas de aprendizagem: o condicionamento clássico, o condicionamento operante, a aprendizagem social e o fenômeno da habituação e da extinção. ${ }^{1}$

\subsection{FATORES SOCIAIS, GRUPAIS OU SISTÊMICOS}

Considera-se que as psicoterapias de grupo e familiar reconhecem que os problemas psicopatológicos individuais possuem grande influência das relações familiares e sociais. A principal estratégia destas psicoterapias está centrada nas intervenções que buscam modificar o ambiente. Disto isto, trabalha-se para que as influências familiares e sociais sejam um ponto de apoio auxiliar a pessoa no seu crescimento emocional e superação das adversidades. ${ }^{1}$

\section{EVIDÊNCIAS CIENTÍFICAS DA AÇÃO DA PSICOTERAPIA}

Atualmente, a ação da psicoterapia em diferentes transtornos mentais pode ser evidenciada a partir de exames de neuroimagem, que emergiram no cenário mundial e possibilitaram estudos mais concretos e não invasivos a respeito dos seus efeitos sobre a neuroplasticidade, fomentando mais investigações sobre a temática. ${ }^{1,7}$

Evidências científicas sobre a ação da abordagem psicoterapêutica nos transtornos mentais indicam que a psicoterapia é o tratamento de escolha ou adjuvante nos seguintes problemas: Transtorno obsessivocompulsivo (TOC), transtorno do pânico, transtorno de estresse pós-traumático (TEPT) e depressão maior. 1,7 
No TOC, estudos evidenciaram alterações no funcionamento cerebral associadas à Terapia Comportamental e Cognitivo-comportamental, por meio de ressonância magnética funcional de repouso ${ }^{1}$ e sugerem que as psicoterapias modificam o funcionamento do cérebro. ${ }^{17}$ Também foi evidenciado que os efeitos da psicoterapia e da farmacologia são comparáveis qualitativamente. ${ }^{18}$

No transtorno de pânico, a psicoterapia se mostrou eficiente quando relacionada ao aumento de ativação em estruturas frontais no hemisfério esquerdo. ${ }^{19}$ Os estudos apontam que as psicoterapias e psicofármacos modificam o funcionamento cerebral em áreas límbicas e pré-frontais em proporções comparáveis. ${ }^{1,7}$

Estudos também evidenciam que pessoas com TEPT e em especial com depressão submetidas à psicoterapia, podem ter alterações no funcionamento cerebral, "associadas a um padrão de ativação/metabolismo em diversos sistemas e regiões no cérebro que se associam com melhora clínica". Entretanto, são necessários mais estudos para certificar tais considerações. ${ }^{1: 112}$ Com base no exposto, certifica-se do papel transformador da psicoterapia na alteração do funcionamento cerebral, podendo associá-la à plasticidade cerebral.

\section{CONSIDERAÇÕES FINAIS}

As psicoterapias são emergentes de um longo processo histórico associado à construção do conhecimento científico. Durante este recorte temporal, é relevante apontar que a psicoterapia passou de uma visão primitiva e imaginária acerca dos processos mentais e seus determinantes, para uma complexa percepção de que as relações do ser humano biopsicossocial com o seu meio impactam na sua saúde e no surgimento de doenças mentais ou orgânicas.

Desta maneira, o curso científico traçado pelos pesquisadores para compreender o funcionamento cerebral associado à psicoterapia, remonta uma trajetória de significativos progressos, como o reconhecimento da neuroplasticidade, que faz menção à relação entre a experiência, fatores sociais, aprendizado e cérebro.

Para tanto, é significativo que os psicoterapeutas continuem construindo o seu campo de conhecimento, incluindo a temática plasticidade neuronal, para qualificar ainda mais, suas técnicas de intervenção no processo de sofrimento humano. Outrossim, estes profissionais necessitam aliar seu arsenal científico ao de outras áreas, para explorarem as diferentes facetas do ser humano, as suas relações consigo mesmo e com a sociedade. Neste entendimento, ressalta-se que pesquisas no campo das neurociências relacionadas aos mecanismos fisiopatológicos das doenças mentais podem trazer melhorias substanciais à clínica do psicoterapeuta, abrindo possibilidades para novas intervenções terapêuticas.

Com base nas considerações ora descritas, conclui-se que a psicoterapia tem papel relevante sobre a modificação do funcionamento cerebral, através da neuroplasticidade. Destaca-se ainda, que as 
investigações sobre a relação entre psicoterapia e cérebro são promissoras, especialmente para a construção de conhecimentos dos transtornos mentais e da prática na clínica. Assim, sinaliza-se que a realização deste estudo pode contribuir para uma lacuna de conhecimento existente nesta área, fomentando o interesse de psicoterapeutas para novos estudos sobre a relação do funcionamento cerebral após as intervenções psicoterápicas e a esperada modificação do comportamento. 


\section{REFERÊNCIAS}

1. Cordioli AV, Grevet EH. Psicoterapias: abordagens atuais. 4. ed. - Porto Alegre: Artmed, 2019.

2. Kendler KS. What psychiatric genetics has taught us about the nature of psychiatric illness and what is left to learn. Mol Psychiatry. 2013;18(10):1058-66.

3. Yurelis, Ginarte Arias: La neuroplasticidad como base biológica de la rehabilitación cognitiva Centro de Investigaciones sobre Envejecimiento, Longevidad y Salud (CITED). GEROINFO. RNPS. 2010. Vol. 2 No. 1.

4. Kundakovic M, Champagne FA. Early-life experience, epigenetics, and the developing brain. Neuropsychopharmacol. 2015;40(1):141-53.

5. Amarante $\mathrm{P}$, Nunes MO. A reforma psiquiátrica no SUS e a luta por uma sociedade sem manicômios. Ciência \& Saúde Coletiva, 23(6):2067-2074, 2018.

6. Osório FL, Silva UCA, Mendes AIF, Pavan-Cândido CC. Psicoterapias: conceitos introdutórios para estudantes da área da saúde. Medicina (Ribeirão Preto, Online.) 2017;50 (Supl.1), jan-fev.:3-21. http://dx.doi.org/10.11606/issn.2176-7262.v50isupl1.p3-21.

7. Cordioli AV. As principais psicoterapias: fundamentos teóricos, técnicas, indicações e contraindicações. In: Cordioli AV, editor. Psicoterapias: abordagens atuais. 3 ed. Porto Alegre: Artmed; 2008. p.19-41.

8. Zhang TY, Labonté B, Wen XL, Turecki G, Meaney MJ. Epigenetic mechanisms for the early environmental regulation of hippocampal glucocorticoid receptor gene expression in rodents and humans. Neuropsychopharmacol. 2013;38(1):111-23.

9. Kandel ER. A new intellectual framework for psychiatry. Am J Psychiatry. 1998;155(4):457-69.

10. Maguire EA. Gadian DG, Johnsrude IS, Good CD, Ashburner J, Frackowiak RS, et al. Navigationrelated structural change in the hippocampi of taxi drivers. Proc Natl Acad Sci U S A. 2000;97(8):4398403.

11. Costa AR, Silva, PLO, Jacóbsen RT. Plasticidade cerebral: conceito(s), contribuições ao avanço científico e estudos brasileiros na área de Letras. Entrepalavras, Fortaleza, v. 9, n. 3, p. 457-476, setdez/2019. http://dx.doi.org/10.22168/2237-6321-31445.

12. Arteni, NS, Alexandre Netto C. Neuroplasticidade. In: Kapczinski F, Quevedo J, Izquierdo I. Bases biológicas dos transtornos psiquiátricos. Porto Alegre: Artmed, 2004.

13. Dalgalarrondo P. Psicopatologia e semiologia dos transtornos mentais. 3. ed. Porto Alegre: Artmed, 2019. $440 \mathrm{p}$.

14. Gulyaeva NV. Molecular mechanisms of neuroplasticity: an expanding universe. Biochemistry. 2017;82(3):237-42.

15. Shaw CA, Lanius RA, Van Den Doel K. The origin of synaptic neuroplasticity: crucial molecules or a dynamical cascade? Brain Res Brain Res Rev. 1994;19(3):241-63. 
16. Fonagy P, Target M. Playing with reality: I. _eory of mind and the normal development of psychic reality. Int J Psychoanal. 1996;77(2):217-33.

17. Schiepek G, Tominschek I, Heinzel S, Aigner M, Dold M, Unger A, et al. Discontinuous patterns of brain activation in the psychotherapy process of obsessive-compulsive disorder: converging results from repeated FMRI and daily self-reports. PloS One. 2013;8(8):e71863.

18. Barsaglini A, Sartori G, Benetti S, Pettersson-yeo W, MechelliA. The effects of psychotherapy on brain function: a systematic and critical review. Prog Neurobiol. 2014;114:1-14.

19. Prasko J, Horácek J, Záleský R, Kopecek M, Novák T, Pasková B, et al. The change of regional brain metabolismo (18FDG PET) in panic disorder during the treatment with cognitive behavioral therapy or antidepressants. Neuro Endocrinol Lett. 2004;25(5):340-8. 